\title{
Efficacy of a commercial supplement added to drinking water in broilers fed aflatoxin-contaminated diets
}

\author{
Tung M. Che ${ }^{1}$, Hien T. Le ${ }^{2}$, Vi Q. Tran ${ }^{2}$, Matthieu Le-Goff ${ }^{3}$, \& Phat T. Luong ${ }^{2}$ \\ ${ }^{1}$ Department of Animal Production, Nong Lam University, Ho Chi Minh City, Vietnam \\ ${ }^{2}$ Olmix Asialand Vietnam, Binh Duong Province, Vietnam \\ ${ }^{3}$ Olmix SA, ZA du Haut du Bois, Bréhan, France
}

\begin{abstract}
ARTICLE INFO
Research Paper

Received: June 01, 2021

Revised: June 22, 2021

Accepted: June 29, 2021
\end{abstract}

\section{Keywords}

Aflatoxin

Broilers

Feed efficiency

Growth performance

\section{* Corresponding author}

Che Minh Tung

Email: tung.cheminh@hcmuaf.edu.vn

\section{ABSTRACT}

The objective of the experiment was to evaluate effects of water supplementation with a commercial supplement (VitalSea ${ }^{\circledR}$ ) on growth performance, mortality and serum concentrations of aspartate aminotransferase (AST) and lactate dehydrogenase (LDH) in broilers fed diets with aflatoxin (AF) contamination. A total of 960 day-old mixed-sex chicks (Ross 308, initial BW: 46.28 $\pm 0.25 \mathrm{~g} /$ chick) were randomly assigned to 1 of 4 treatments. The treatments included (1) basal diet without AF contamination and supplementation (negative control, NC), (2) AFcontaminated diet without supplementation (positive control, $\mathrm{PC}$ ), (3) AF-contaminated diet + water supplementation with 0.5 $\mathrm{mL}$ VitalSea ${ }^{\circledR} / 10 \mathrm{~kg} \mathrm{BW}$ (VitalSea 1) and (4) AF-contaminated diet + water supplementation with $1.0 \mathrm{~mL}$ VitalSea ${ }^{\circledR} / 10 \mathrm{~kg} \mathrm{BW}$ (VitalSea 2). Each treatment was replicated with 8 pens of 30 birds ( $50 \%$ male, $50 \%$ female) each. Contaminated diets containing 30 $\mu \mathrm{g} \mathrm{AF} / \mathrm{kg}$ were fed to birds for Phase 1 (d 1-21) only. Water supplemented with VitalSea ${ }^{\circledR}$ was administered to birds for 5 days (d 22-26). In Phase 1 (d 1-21), there were no differences in ADG and ADFI among treatments $(P>0.05)$. In Phase $2(\mathrm{~d} 22-35)$, there was a trend that the ADG of VitalSea $1(68.66 \mathrm{~g} / \mathrm{d})$ and VitalSea $2(68.56 \mathrm{~g} / \mathrm{d})$ was higher $(P<0.06)$ than that of the PC $(62.61$ $\mathrm{g} / \mathrm{d})$. Water supplemented with VitalSea ${ }^{\circledR}$ improved the FCR of broilers compared with the PC $(P<0.01)$. Over a 5 -week study, broilers of the PC had a worse FCR than those of the other treatments $(P<0.01)$. At $\mathrm{d} 21$, the serum LDH concentration of the $\mathrm{PC}$ was higher than that of the NC $(P=0.026)$. Briefly, addition of VitalSea ${ }^{\circledR}$ to drinking water for 5 days improved growth rate and feed efficiency of broilers fed AF-contaminated diets.

Cited as: Che, T. M., Le, H. T., Tran, V. Q., Le-Goff, M., \& Luong, P. T. (2021). Efficacy of a commercial supplement added to drinking water in broilers fed aflatoxin-contaminated diets. The Journal of Agriculture and Development 20(3), 32-40.

\section{Introduction}

Aflatoxins (AF) are a group of mycotoxins naturally produced as secondary metabolites by the fungus Aspergillus and are potent hepatotoxins and carcinogens in the liver. Aflatoxins commonly contaminate a wide variety of feedstuffs, especially in tropical and subtropical regions of the world where conditions are favorable for the growth of mold (Molina-Alvarado et al., 2017; Nakavuma et al., 2020). Ditta et al. (2019) reported that globally about $25 \%$ of agricultural products were contaminated with $\mathrm{AF}$ and other mycotoxins in the world, especially in Africa, Asia and Latin America, resulting in decreased food/feed values and thereby causing economic 
losses to farmers.

In chickens, it has been shown that the effects of $\mathrm{AF}$ include liver damage, decreased feed intake and growth rate, poor feed utilization and increased susceptibility to diseases. For instance, Raju and Devegowda (2000) showed that the final BW at 35 days of age in broilers fed a diet with $300 \mu \mathrm{g} \mathrm{AFB}_{1} / \mathrm{kg}$ was reduced by $21 \%$. Even feeding a diet containing as low as $20 \mu \mathrm{g} \mathrm{AFB}_{1} / \mathrm{kg}$ for 3 weeks decreased the weight gain of broilers by $5 \%$ (Kana et al., 2010). Further, AFcontaminated diets fed to broilers also resulted in changes in serum levels of some biochemical parameters associated with liver health and functions (Yunus et al., 2011; Pizzolitto et al., 2013). Malekinezhad et al. (2021) found that feeding $\mathrm{AF}$-contaminated diets increased the serum aspartate aminotransferase (AST), lactate dehydrogenase $(\mathrm{LDH})$ and alanine aminotransferase (ALT).

There have been many chemical and biological techniques developed to detoxify AFcontaminated grains and complete feeds, with various effectiveness and ease of application. Thus, there is a need for new supplements or synergistic combinations to more efficiently alleviate the deleterious effects of AF and restore liver health and productivity. It has been shown that yeast extracts have the ability to reduce some of the adverse effects of aflatoxicosis in broilers and layers (Zaghini et al., 2005; Matur et al., 2010; Azizpour \& Moghadam, 2015). Some plant extracts can also be used in poultry diets to counteract the toxicity of AF (Fouad et al., 2019). Recently, sulfated polysaccharides isolated from marine algae have been of potential interest because of their antioxidant, anticancer, antidiabetic, antimicrobial and gastroprotective effects (Manlusoc et al., 2019). In the present study, we hypothesized that the combination of marine sulfated polysaccharides $\left(\mathrm{MSP}_{\text {lipid }}^{\circledR}\right)$, organic acids and yeast fractions could be an alternative solution to mitigate the negative impacts of $\mathrm{AF}$ on liver status and improve growth performance of broilers after exposure to AFcontaminated diets for 3 weeks. Therefore, the objective of the experiment was to evaluate effects of water supplementation with a commercial supplement (VitalSea ${ }^{\circledR}$ ) on growth performance, mortality and serum concentrations of AST and $\mathrm{LDH}$ in broilers fed diets with a low level of AF contamination.

\section{Materials and Methods}

\subsection{Experimental design, animals and housing}

The experiment was conducted using 960 dayold mixed-sex chicks (Ross 308, initial BW: $46.28 \pm 0.25 \mathrm{~g} /$ chick). The birds were randomly assigned to 1 of 4 treatments in a completely randomized design. The treatments included (1) basal diet without AF contamination and supplementation (negative control, NC), (2) AF-contaminated diet without supplementation (positive control, PC), (3) AF-contaminated diet + water supplementation with $0.5 \mathrm{~mL}$ VitalSea ${ }^{\circledR} / 10 \mathrm{~kg} \mathrm{BW}$ (VitalSea 1) and (4) AFcontaminated diet + water supplementation with $1.0 \mathrm{~mL}$ VitalSea ${ }^{\circledR} / 10 \mathrm{~kg} \mathrm{BW}$ (VitalSea 2). The birds were housed in floor pens in an open-sided house and each pen measured $2.5 \mathrm{~m}$ length $\mathrm{x} 1.2$ $\mathrm{m}$ width. Each treatment had 8 replicate pens with 30 birds ( $50 \%$ male, $50 \%$ female) per pen. The experiment lasted for 5 weeks. The AF challenge model of the experiment is presented in Table 1 .

\subsection{Experimental diets and animal feeding}

The experimental diets were formulated to meet the nutritional requirements of broilers during the experimental period (NRC, 1994). The birds were fed a 2-Phase feeding program: Phase 1 (1-21 d old) and Phase 2 (22-35 d old). The ingredient composition of the experimental diet is presented in Table 2. The AF-contaminated diets were obtained by including corn which was naturally contaminated with $\mathrm{AF}$ and its $\mathrm{AF}$ concentration was predetermined before the start of the experiment. Birds were fed the AF-contaminated diets during Phase 1 only and a normal diet during Phase 2. The analyzed AF concentration of the contaminated diets was $30 \mu \mathrm{g} / \mathrm{kg}$ (Table 3 ). The AF concentration of the non-contaminated Phase 1 and Phase 2 diets was $2 \mu \mathrm{g} / \mathrm{kg}$ and is presented in Table 3. Diets were in mash form and contained no antibiotics and mycotoxin binders. All birds had free access to water and feed at all times.

\subsubsection{Feed sample and aflatoxin analyses}

Feed samples were ground to pass through a 1$\mathrm{mm}$ screen before analysis and analyzed according to the standard methods. Diet samples were 
Table 1. The aflatoxin challenge model of the experiment

\begin{tabular}{|c|c|c|c|c|}
\hline \multirow{2}{*}{ Age } & \multicolumn{4}{|c|}{ Treatments } \\
\hline & Negative control & $\begin{array}{l}\text { Positive } \\
\text { control }\end{array}$ & VitalSea 1 & VitalSea 2 \\
\hline $\begin{array}{c}\text { Phase } 1 \text { (d 1-21) } \\
\text { Challenging period }\end{array}$ & $\begin{array}{c}\text { Non-aflatoxin } \\
\text { contaminated diet }\end{array}$ & \multicolumn{3}{|c|}{ Aflatoxin-contaminated diet } \\
\hline Phase 2 (d 22-35) & $\begin{array}{c}\text { Basal diet } 2 \\
\text { without VitalSea }{ }^{\circledR}\end{array}$ & $\begin{array}{c}\text { Basal diet } 2 \\
\text { without } \\
\text { VitalSea }^{\circledR}\end{array}$ & $\begin{array}{l}\text { Basal diet } 2+ \\
\text { VitalSea }^{\circledR}(0.5 \\
\text { mL/10 kg BW } \\
\text { during } 5 \text { days, } \\
\text { d 22-26) }\end{array}$ & $\begin{array}{l}\text { Basal diet } 2+ \\
\text { VitalSea }^{\circledR}(1.0 \\
\text { mL/10 kg BW } \\
\text { during } 5 \text { days, } \\
\text { d 22-26) }\end{array}$ \\
\hline
\end{tabular}

Table 2. Ingredient composition of the experimental diets (as-fed basis)

\begin{tabular}{|c|c|c|}
\hline \multirow{2}{*}{ Ingredients, $\%$} & \multicolumn{2}{|c|}{ Days of age } \\
\hline & $1-21$ (Phase 1) & $22-35$ (Phase 2$)$ \\
\hline Corn, ground ${ }^{1}$ & 58.23 & 60.12 \\
\hline Soybean meal, $46 \%$ & 35.60 & 33.50 \\
\hline Soybean oil & 2.10 & 2.70 \\
\hline DL-Methionine, $99 \%$ & 0.14 & 0.09 \\
\hline Lysine, $78.8 \%$ & 0.20 & 0.08 \\
\hline Salt & 0.30 & 0.30 \\
\hline Limestone & 1.80 & 1.66 \\
\hline $\operatorname{MCP}(15,23)$ & 1.28 & 1.20 \\
\hline Vitamin and mineral premix ${ }^{2,3}$ & 0.25 & 0.25 \\
\hline Pigment & 0.10 & 0.10 \\
\hline
\end{tabular}

${ }^{1}$ Phase 1: Normal corn or aflatoxin (AF)-contaminated corn; Phase 2: normal corn only.

${ }^{2}$ Supplied per kg of feed (Phase 1): vitamin A (12000 IU), vitamin D3 (3500 IU), vitamin E (35 mg), vitamin K (4 mg), vitamin B1 $(4 \mathrm{mg})$, vitamin B2 $(7 \mathrm{mg})$, niacin $(60 \mathrm{mg})$, vitamin B5 $(17.5 \mathrm{mg})$, vitamin B6 $(4 \mathrm{mg})$, vitamin B12 $(15 \mu \mathrm{g})$, folic acid

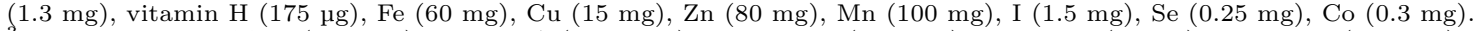

${ }^{3}$ Supplied per kg of feed (Phase 2): vitamin A (10000 IU), vitamin D3 (3000 IU), vitamin E (25 mg), vitamin K (3.13 mg), vitamin B1 (3.13 mg), vitamin B2 $(5 \mathrm{mg})$, niacin $(44 \mathrm{mg})$, vitamin B5 $(12.5 \mathrm{mg})$, vitamin B6 (3.13 mg), vitamin B12 (11 $\mathrm{\mu g})$, folic acid $(1.0 \mathrm{mg})$, vitamin H (125 pg), Fe (60 mg), Cu (15 mg), Zn (70 mg), Mn (90 mg), I (1.5 mg), Se (0.25 mg), Co (0.3 mg).

analyzed for DM (EC 152/2009), CP (AOAC 2001.11), crude fat (TCVN 4331:2001), crude fiber (AOCS Ba-6a-05), ash (EC 152/2009), Ca (GE297-ICP MS) and P (GE297-ICP MS). The nutrient analyses were performed by Upscience Vietnam in Binh Duong province, Vietnam. The aflatoxin concentrations of contaminated corn and feed samples were determined by LC/MSMS method (Labocea, Britany, France). The analyzed nutrient composition and $\mathrm{AF}$ concentration of the experimental diets is presented in Table 3.

\subsubsection{VitalSea ${ }^{\circledR}$ administration}

Drinking water supplemented with VitalSea ${ }^{\circledR}$ was administered to birds for 5 consecutive days (d 22 to d 26) after 21-d exposure to AFcontaminated diets. The VitalSea ${ }^{\circledR}$ was added to drinking water at $0.5 \mathrm{~mL}$ of VitalSea ${ }^{\circledR}$ per 10 $\mathrm{kg}$ of BW in the VitalSea 1 treatment and at 1.0 $\mathrm{mL}$ of VitalSea ${ }^{\circledR}$ per $10 \mathrm{~kg}$ of BW in the VitalSea 2 treatment. The VitalSea ${ }^{\circledR}$ contained $\mathrm{MSP}_{\text {lipid }}^{\circledR}$, yeast fractions and a blend of organic acids. This product was provided by Olmix Asialand Co. Ltd, Binh Duong province, Vietnam.

\subsubsection{Assessment of growth performance, flock uniformity and mortality rate}

The initial BW of chicks in each pen was recorded at the beginning of the experiment. Subsequent measurements of the bird weights and feed intake were determined at 21 and 35 days of age. The ADG, ADFI and FCR were calculated on a per-pen basis. Day old chicks were weighed individually and subsequently at 21 and 35 days of age for measurement of flock uniformity. The flock uniformity was calculated as the percent of the flock that was within $\pm 10 \%$ of the mean BW. 
Table 3. Analyzed nutrient composition and aflatoxin concentration of the experimental diets (as-fed basis) ${ }^{1}$

\begin{tabular}{lccc}
\hline \multirow{2}{*}{ Items } & \multicolumn{2}{c}{ Phase 1 } & \multirow{2}{*}{ Phase 2} \\
\cline { 2 - 3 } & Negative control & Positive control & \\
\hline ME, kcal $/ \mathrm{kg}^{2}$ & 3000 & 3000 & 3050 \\
DM, \% & 88.45 & 89.09 & 88.39 \\
Crude protein, \% & 23.59 & 22.40 & 22.02 \\
Crude fat, \% & 3.89 & 3.95 & 4.57 \\
Crude fiber, \% & 2.66 & 2.35 & 2.42 \\
Ash, \% & 5.94 & 5.88 & 5.69 \\
Ca, \% & 1.01 & 0.99 & 0.88 \\
Total phosphorus, \% & 0.62 & 0.60 & 0.61 \\
Aflatoxin, $\mu \mathrm{g} / \mathrm{kg}^{3}$ & 2.00 & 30.00 & 2.00 \\
\hline
\end{tabular}

${ }^{1}$ The analysis was performed by Upscience Vietnam in Binh Duong province, Vietnam.

${ }^{2}$ Calculated.

${ }^{3}$ Analyzed by Labocea laboratory (Britany, France).

Table 4. Effects of water supplementation with VitalSea ${ }^{\circledR}$ on live body weight of broilers (g/bird) fed aflatoxin-contaminated diets

\begin{tabular}{|c|c|c|c|c|c|c|}
\hline \multirow{2}{*}{ Age, d } & \multicolumn{4}{|c|}{ Treatments $^{1}$} & \multirow{2}{*}{ SEM } & \multirow{2}{*}{$P$} \\
\hline & $\mathrm{NC}$ & $\mathrm{PC}$ & VitalSea 1 & VitalSea 2 & & \\
\hline 1 & 46.19 & 46.20 & 46.36 & 46.39 & 0.088 & 0.278 \\
\hline 21 & 767.28 & 765.46 & 774.87 & 795.85 & 9.843 & 0.136 \\
\hline 35 & $1675.39^{\mathrm{ab}}$ & $1636.53^{b}$ & $1726.32^{\mathrm{ab}}$ & $1754.94^{\mathrm{a}}$ & 29.487 & 0.039 \\
\hline
\end{tabular}

${ }_{1}^{1} 8$ replicate pens/treatment and 30 birds/pen; NC: negative control; PC: positive control; VitalSea 1: $0.5 \mathrm{~mL}$ of VitalSea ${ }^{\circledR}$ per $10 \mathrm{~kg}$ of live BW; VitalSea 2: $1.0 \mathrm{~mL}$ of VitalSea ${ }^{\circledR}$ per $10 \mathrm{~kg}$ of live BW; VitalSea ${ }^{\circledR}$ was administered to broilers from d $22-26$.

${ }^{\mathrm{a}-\mathrm{b}}$ Within a row, means without a common superscript differ $(P<0.05)$.

The number of dead or removed birds from each pen was recorded daily to calculate the mortality rate.

\subsubsection{Blood collection and measurements of serum AST and LDH}

Two male birds per pen were randomly selected for collection of blood samples from a wing vein at 21 days of age and subsequent blood samples were taken from the same birds at 26 and 35 days of age. Two milliliters of blood from each bird were collected into a tube containing no anticoagulant. The blood was allowed to clot at room temperature and stored at $4^{\circ} \mathrm{C}$ before separation of serum by centrifugation $(3000 \mathrm{x} \mathrm{g}$ for $10 \mathrm{~min}$ at room temperature). Serum concentrations of AST and LDH were measured by specific commercial kits (AFG Bioscience, IL, USA) using an autoanalyzer (Biotek, Vermont, USA).

\subsubsection{Statistical analysis}

Data were analyzed as a completely randomized design by ANOVA using the GLM proce- dure (SAS Inst. Inc., Cary, NC). The pen was considered the experimental unit for live BW, ADFI, ADG and FCR, whereas one bird was considered the experimental unit for the other parameters. When a significant $\mathrm{F}$ value for treatment means was observed in the analysis of variance, the treatment means were compared using Tukey's test. To test the effect of AF contamination on the mortality of broilers during the AF exposure period (Phase 1), the mortality data were pooled from the 3 treatments with AF-contaminated diet. The flock uniformity and mortality rate among the treatments was compared by the Chi-square test. Treatment effects were considered significant at $P<0.05$, whereas a trend for a treatment effect was noted when $P$ $<0.1$.

\section{Results}

\subsection{Growth performance}

No differences in the BW of broilers were found at 1 and 21 days of age among treatments $(P$ $>0.05$; Table 4). At d 35, the BW of birds in 
Table 5. Effects of water supplementation with VitalSea ${ }^{\circledR}$ on growth performance of broilers (g/bird) fed aflatoxin-contaminated diets

\begin{tabular}{|c|c|c|c|c|c|c|}
\hline \multirow{2}{*}{ Age, d } & \multicolumn{4}{|c|}{ Treatments $^{1}$} & \multirow{2}{*}{ SEM } & \multirow{2}{*}{$P$} \\
\hline & $\mathrm{NC}$ & $\mathrm{PC}$ & VitalSea 1 & VitalSea 2 & & \\
\hline \multicolumn{7}{|l|}{ D 1-21 } \\
\hline ADFI, $\mathrm{g}$ & 46.44 & 46.73 & 47.89 & 47.76 & 0.554 & 0.182 \\
\hline $\mathrm{ADG}, \mathrm{g}$ & 33.99 & 33.87 & 34.15 & 34.71 & 0.449 & 0.572 \\
\hline FCR & 1.367 & 1.380 & 1.402 & 1.376 & 0.009 & 0.060 \\
\hline \multicolumn{7}{|l|}{ D $22-35$} \\
\hline ADFI, $\mathrm{g}$ & 120.57 & 121.41 & 121.75 & 126.33 & 2.122 & 0.238 \\
\hline $\mathrm{ADG}, \mathrm{g}$ & 64.92 & 62.61 & 68.66 & 68.56 & 1.584 & 0.029 \\
\hline FCR & $1.860^{\mathrm{ab}}$ & $1.943^{\mathrm{b}}$ & $1.776^{\mathrm{a}}$ & $1.845^{\mathrm{a}}$ & 0.025 & 0.001 \\
\hline \multicolumn{7}{|l|}{ D 1-35 } \\
\hline ADFI, g & 73.52 & 74.19 & 74.90 & 75.75 & 0.889 & 0.345 \\
\hline $\mathrm{ADG}, \mathrm{g}$ & 45.29 & 44.43 & 46.77 & 46.76 & 0.665 & 0.047 \\
\hline FCR & $1.624^{\mathrm{a}}$ & $1.670^{\mathrm{b}}$ & $1.602^{\mathrm{a}}$ & $1.620^{\mathrm{a}}$ & 0.011 & 0.001 \\
\hline
\end{tabular}

${ }^{1} 8$ replicate pens/treatment and 30 birds/pen; NC: negative control; PC: positive control; VitalSea 1: $0.5 \mathrm{~mL}$ of VitalSea ${ }^{\circledR}$ per $10 \mathrm{~kg}$ of live BW; VitalSea 2: $1.0 \mathrm{~mL}$ of VitalSea ${ }^{\circledR}$ per $10 \mathrm{~kg}$ of live BW; VitalSea ${ }^{\circledR}$ was administered to broilers from d $22-26$. ${ }^{\mathrm{a}-\mathrm{b}}$ Within a row, means without a common superscript differ $(P<0.05)$.

the VitalSea 2 group (1754.94 g/bird) was higher $(P<0.05)$ than that of birds in the PC group (1636.53 g/bird). There were no differences in ADFI among treatments at any Phases or for the overall period $(P>0.05$; Table 5$)$.

In Phase 1, no differences in ADG were found among treatments $(P=0.572$, Table 5$)$. Broilers of the VitalSea 1 group tended to have a higher FCR than that of the NC group $(P<0.06)$. In Phase 2, water supplementation with VitalSea ${ }^{\circledR}$ tended to increase the ADG of broilers compared with the PC group $(P<0.06)$. The VitalSea 1 and VitalSea 2 groups also had a better FCR than the PC group $(P<0.01)$. For the overall period, the ADG of broilers consuming water with $\mathrm{Vi}$ talSea $1(46.77 \mathrm{~g} / \mathrm{d})$ and VitalSea $2(46.76 \mathrm{~g} / \mathrm{d})$ tended to be higher $(P<0.09)$ than that of broilers in the PC group $(44.43 \mathrm{~g} / \mathrm{d})$. In addition, the FCR of the PC group (1.670) was higher than that of the NC (1.624), VitalSea 1 (1.602) and VitalSea $2(1.620)$ groups $(P<0.01)$.

\subsection{Flock uniformity and mortality rate}

There were no differences in the flock uniformity of broilers among treatments at $\mathrm{d} 1$ and $\mathrm{d} 21$ $(P>0.05$; Figure 1$)$. At d 35 , no differences were found for the flock uniformity of broilers among treatments $(P>0.05)$, although the flock uniformity of broilers in the VitalSea 1 group (61.9\%) was numerically higher than that of broilers in the NC $(58.6 \%)$, PC $(54.5 \%)$ and VitalSea $2(56.4 \%)$ groups. As shown in Figure 2A, the mortality rate of the NC group $(2.5 \%)$ was lower $(P<0.05)$ than the average mortality rate of the 3 AFcontaminated groups (5.7\%) during d 1-21 (period of AF exposure). No differences $(P>0.05)$ in the mortality rate were observed among treatments during d 22-35 (Figure 2B).

\subsection{Serum concentrations of AST and LDH}

At 21 days of age, there were no differences in the serum concentration of AST among treatments $(P=0.118$; Table 6$)$. However, the serum $\mathrm{LDH}$ concentration of broilers in the $\mathrm{PC}$ group $(2214.4 \mathrm{U} / \mathrm{L})$ was higher $(P=0.026)$ than that of broilers in the NC group $(2078.1 \mathrm{U} / \mathrm{L})$, but was not different from that of broilers in the VitalSea $1(2122.0 \mathrm{U} / \mathrm{L})$ and VitalSea 2 (2144.7 $\mathrm{U} / \mathrm{L})$ groups $(P>0.05)$. At 26 and 35 days of age, no differences in the serum concentrations of AST and LDH were found among treatments $(P$ $>0.05)$.

\section{Discussion}

Aflatoxins are a common contaminant of poultry feeds in the tropical and subtropical areas. For example, Shareef (2010) found that AF was a major mycotoxin group (91.1\%) with an average concentration of $179.1 \mathrm{\mu g} / \mathrm{kg}$ in different poultry feed samples collected in Pakistan. In Vietnam, a 5-year survey (from 2012-2017) showed that the total AF incidence and total AF mean 


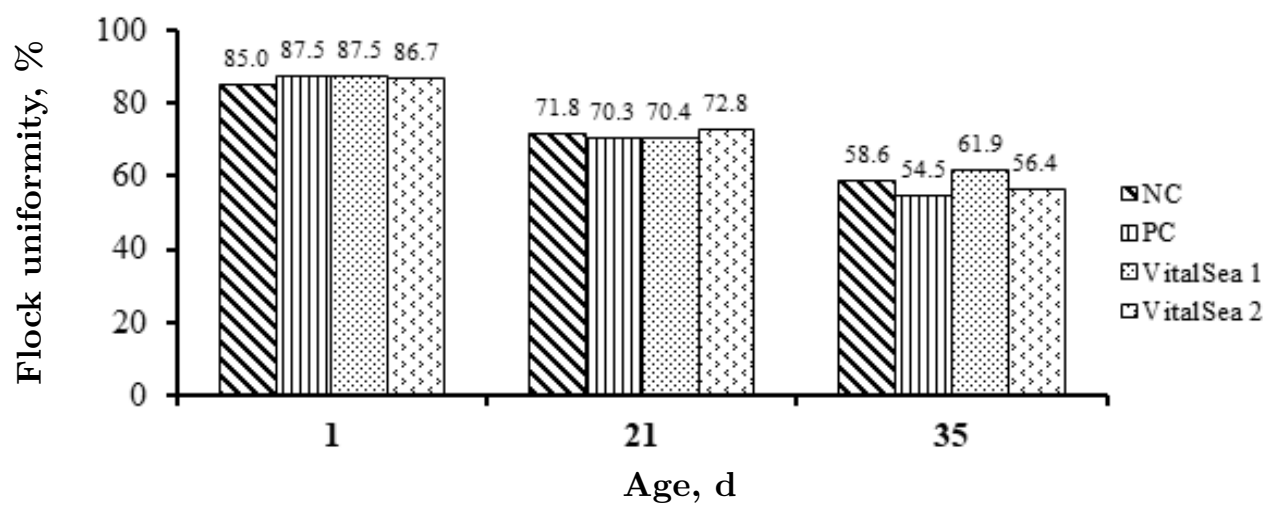

Figure 1. Effects of water supplementation with VitalSea ${ }^{\circledR}$ on the flock uniformity of broilers fed aflatoxincontaminated diets $(P>0.05)$. NC: negative control; PC: positive control; VitalSea 1: $0.5 \mathrm{~mL}$ of VitalSea ${ }^{\circledR}$ per $10 \mathrm{~kg}$ of live BW; VitalSea 2: $1.0 \mathrm{~mL}$ of VitalSea ${ }^{\circledR}$ per $10 \mathrm{~kg}$ of live BW; VitalSea ${ }^{\circledR}$ was administered to broilers from d 22-26; There were 240 birds/treatment.

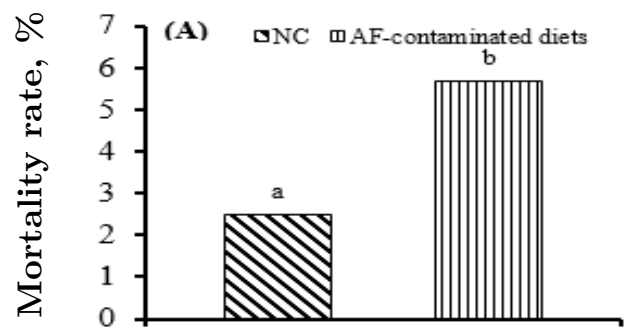

1-21 d old

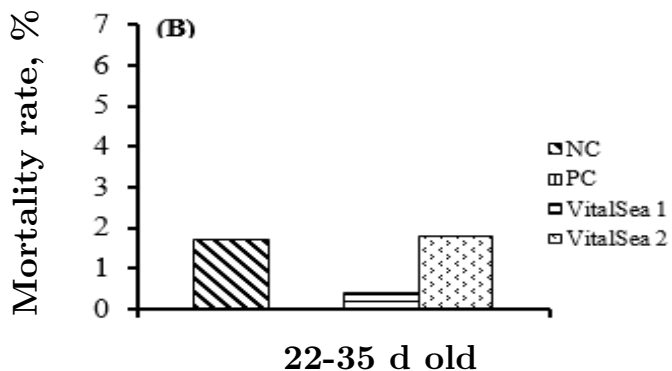

22-35 d old

Figure 2. Effects of water supplementation with VitalSea ${ }^{\circledR}$ on the mortality rate of broilers fed aflatoxincontaminated diets. (A) AF exposure period: $\mathrm{NC}$ (non-AF contaminated diet) vs. 3 AF-contaminated diets (PC, VitalSea 1, VitalSea 2). (B): NC: negative control; PC: positive control; VitalSea 1: $0.5 \mathrm{~mL}$ of VitalSea ${ }^{\circledR}$ per $10 \mathrm{~kg}$ of live BW; VitalSea 2: $1.0 \mathrm{~mL}$ of VitalSea ${ }^{\circledR}$ per $10 \mathrm{~kg}$ of live BW; VitalSea ${ }^{\circledR}$ was administered to broilers from d 22-26. There were 240 birds/treatment. ${ }^{\text {a,b }}$ Means with different superscript letters differ $(P$ $<0.05)$.

Table 6. Serum concentration of aspartate aminotransferase (AST) and lactate dehydrogenase (LDH) of broilers fed aflatoxin-contaminated diets with and without water supplementation of VitalSea ${ }^{\circledR}$

\begin{tabular}{|c|c|c|c|c|c|c|}
\hline \multirow{2}{*}{ Age, d } & \multicolumn{4}{|c|}{ Treatments $^{1}$} & \multirow{2}{*}{ SEM } & \multirow{2}{*}{$P$} \\
\hline & $\mathrm{NC}$ & $\mathrm{PC}$ & VitalSea 1 & VitalSea 2 & & \\
\hline \multicolumn{7}{|l|}{$\bar{D} 21$} \\
\hline $\mathrm{AST}, \mathrm{U} / \mathrm{L}$ & 280.8 & 232.9 & 277.4 & 318.9 & 28.648 & 0.118 \\
\hline $\mathrm{LDH}, \mathrm{U} / \mathrm{L}$ & $2078.1^{\mathrm{b}}$ & $2214.4^{\mathrm{a}}$ & $2122.0^{\mathrm{ab}}$ & $2144.7^{\mathrm{ab}}$ & 32.712 & 0.026 \\
\hline \multicolumn{7}{|l|}{ D 26} \\
\hline $\mathrm{AST}, \mathrm{U} / \mathrm{L}$ & 208.9 & 194.4 & 195.8 & 216.7 & 7.876 & 0.150 \\
\hline $\mathrm{LDH}, \mathrm{U} / \mathrm{L}$ & 909.1 & 991.9 & 946.4 & 1012.5 & 39.007 & 0.240 \\
\hline \multicolumn{7}{|l|}{ D 35} \\
\hline $\mathrm{AST}, \mathrm{U} / \mathrm{L}$ & 270.8 & 266.8 & 256.6 & 270.7 & 21.397 & 0.963 \\
\hline $\mathrm{LDH}, \mathrm{U} / \mathrm{L}$ & 828.5 & 972.0 & 899.0 & 1035.2 & 93.382 & 0.394 \\
\hline
\end{tabular}

${ }^{1} 16$ birds/treatment; NC: negative control; PC: positive control; VitalSea 1: $0.5 \mathrm{~mL}$ of VitalSea ${ }^{\circledR}$ per $10 \mathrm{~kg}$ of live BW; VitalSea 2: $1.0 \mathrm{~mL}$ of VitalSea ${ }^{\circledR}$ per $10 \mathrm{~kg}$ of live BW; VitalSea ${ }^{\circledR}$ was administered to broilers from d 22-26.

${ }^{\mathrm{a}-\mathrm{b}}$ Within a row, means without a common superscript differ $(P<0.05)$.

concentration of corn samples were $27 \%$ and 2017). Aflatoxins are of major importance be$16 \mathrm{\mu g} / \mathrm{kg}$, respectively (Molina-Alvarado et al., cause of their toxicity. Feeding AF-contaminated 
feedstuffs to animals impaired feed intake, feed efficiency and/or animal health (Dersjant-Li et al., 2003; Magnoli et al., 2011; Yunus et al., 2011). According to Rawal et al. (2010), AF contamination is practically unavoidable universally. Therefore, the combination of different bioactive ingredients that can not only reduce the toxic effects of AF but also enhance liver functions and gut health could be a promising strategy to improve the overall health and performance of animals.

Our study showed that feeding a diet containing $30 \mu \mathrm{g} \mathrm{AF} / \mathrm{kg}$ can result in negative effects on health and feed efficiency of young broilers. As shown in Figure 2A, broilers fed AFcontaminated diets had a higher mortality rate than those fed the NC diet during the AF exposure period. Furthermore, consuming the AFcontaminated diets for 21 days post-hatching also reduced the overall feed efficiency of broilers compared with the NC and VitalSea ${ }^{\circledR}$ groups (Table 5). According to Richard (2007) and Denli et al. (2009), AF toxicity is affected by different factors including AF level, duration of dietary exposure, species, sex, breed and age of animals. For instance, the autopsy of dead birds in our study revealed that $78 \%$ of dead birds fed the AF-contaminated diets showed paleness and yellow discoloration of the liver. It was also observed that the birds with yellowish colored liver died mainly during d 1-11 (68.8\%) as compared with d 12-21 (31.2\%). Young animals are often more susceptible to AF than older ones due to the lack of well-developed hepatic enzymatic systems required to detoxify mycotoxins (Kermanshahi, 2007; Ditta et al., 2019). Besides, the results of our study agree with those of previous studies. Yang et al. (2012) showed that diets contaminated with $36.9 \mathrm{\mu g} \mathrm{AFB}_{1} / \mathrm{kg}$ decreased the weight gain, feed consumption and duodenal villus height of broilers during 1-21 days of age. It was also reported that diets containing 20 and $22 \mu \mathrm{g} \mathrm{AFB}_{1} / \mathrm{kg}$ reduced the apparent digestibility of ducks and growth performance of broilers, respectively (Han et al., 2008; Saminathan et al., 2018). Additionally, although AFcontaminated diet did not affect the serum AST, it did increase the serum concentration of LDH at $\mathrm{d} 21$ (Table 6 ). This implies that consuming the AF-contaminated diet, to a certain extent, might have caused liver malfunction and/or damage leading to the release of LDH into the bloodstream. Liver lesions such as fat vacuoles and hepatocellular necrosis with perilobular location were observed in broilers fed a diet containing $50 \mu \mathrm{g}$ $\mathrm{AFB}_{1} / \mathrm{kg}$ (Magnoli et al., 2011). Valchev et al. (2014) reported that AF not only caused liver lesions but also increased the serum level of LDH. Generally, diets contaminated with AF increased the FCR, mortality rate and serum LDH concentration of broilers.

In the present study, addition of VitalSea ${ }^{\circledR}$ to the drinking water for 5 consecutive days immediately after 21 days of AF exposure improved the final BW, growth rate and feed efficiency of broilers for both Phase 2 and the overall period (Table 5). This improvement may be associated with the bioactive components combined in the VitalSea ${ }^{\circledR}$, such as $\mathrm{MSP}_{\text {lipid }}^{\circledR}$, yeast fractions and a blend of organic acids. Aflatoxins are known to alter the synthesis, absorption and transport of lipids to extra-hepatic tissues. Their metabolites can significantly increase the hepatic lipid peroxide level which negatively affects cellular membrane integrity leading to cell damage. For instance, Liu et al. (2018) showed that feeding 40 $\mu \mathrm{g} \mathrm{AFB}_{1} / \mathrm{kg}$ to broilers decreased the ADG and FCR, and increased the intestinal lesions. It has been shown that the use of MSP can improve not only lipid metabolism but also antioxidant capacity in animals (Manlusoc et al., 2019). Bussy et al. (2020) reported that DigestSea ${ }^{\circledR}$, a product containing $\mathrm{MSP}_{\text {lipid }}^{\circledR}$, improved liver function and laying performance of turkey breeders. In addition, the combination of MSP ${ }^{\circledR}$ and organic acids was also found to improve the FCR of broilers during the finishing period (Che et al., 2019). In recent years, yeast extracts have been of potential interest due to their AF detoxification ability and positive effects on gut health. Matur et al. (2010) showed that dietary supplementation of $S$. cerevisiae extract reduced the toxic effects of $\mathrm{AF}$ on pancreatic lipase and chymotrypsin activity in laying breeder hens. Also, it was suggested that yeast cell wall could partially protect the growth performance and intestinal health of broilers concurrently challenged with AF and necrotic enteritis (Liu et al., 2018). Briefly, VitalSea ${ }^{\circledR}$ with a combination of different bioactive compounds showed its effectiveness in ameliorating the productivity of broilers after 3-week exposure to AF.

\section{Conclusions}

Feeding AF-contaminated diets negatively affected the productivity and health of broilers not only during the $\mathrm{AF}$ exposure but also in the 
subsequent period. Water supplementation with VitalSea ${ }^{\circledR}$ can help restore the performance of broilers after AF exposure. As contamination of poultry feeds with $\mathrm{AF}$ is quite common in the tropical countries and other parts of the world, the addition of VitalSea ${ }^{\circledR}$ to drinking water could be a useful tool in supporting the liver health and growth performance of broilers.

\section{Conflicts of interest}

The authors declare no conflicts of interest.

\section{References}

Azizpour, A., \& Moghadam, N. (2015). Effects of yeast glucomannan and sodium bentonite on the toxicity of aflatoxin in broilers. Bazilian Journal of Poultry Science 17, 7-13.

Bussy, F., Le-Goff, M., Biesse, M., Guriec, N., Delarue, J., Mathiaud, O., and Collén, P. N. (2020). An algal extract improves liver function and laying performance of turkey breeders. Journal of US-China Medical Science 17, 250-256.

Che, T. M., Le, H. T., Tran, V. Q., Berdeaux, D., Meallet, V., \& Guillaume, M. (2019). Use of marine sulfated polysaccharide as an alternative to antibiotics in the diet of broilers. The Journal of Agriculture and Development 18(3), 1-26.

Denli, M., Blandon, J. C., Guynot, M. E., Salado, S., \& Perez, J. F. (2009). Effects of dietary AflaDetox on performance, serum biochemistry, histopathological changes, and aflatoxin residues in broilers exposed to aflatoxin B1. Poultry Science 88(7), 1444-1451.

Dersjant-Li, Y., Verstegen, M. W. A., \& Gerrits, W. J. J. (2003). The impact of low concentrations of aflatoxin, deoxynivalenol or fumonisin in diets on growing pigs and poultry. Nutrition Research Reviews 16(2), 223239.

Ditta, Y. A., Mahad, A., \& Bacha, U. (2019). Aflatoxins: their toxic effect on poultry and recent advances in their treatment. In P. B., Njobeh, \& F., Stepman (Eds).. Mycotoxins: Impact and management strategies (125-147). London, UK: IntechOpen.

Fouad, A. M., Ruan, D., El-Senousey, H. K., Chen, W., Jiang, S., \& Zheng, C. (2019). Harmful effects and control strategies of aflatoxin $\mathrm{B}_{1}$ produced by Aspergillus flavus and Aspergillus parasiticus strains on poultry: Review. Toxins 11, 176.

Han, X. Y., Huang, Q. C., Li, W. F., Jiang, J. F., \& $\mathrm{Xu}, \mathrm{Z}$. R. (2008). Changes in growth performance, digestive enzyme activities and nutrient digestibility of cherry valley ducks in response to aflatoxin B1 levels. Livestock Science 119, 216-220.

Kana, J. R., Teguia, A., \& Tchoumboue, J. (2010). Effect of dietary plant charcoal from Canarium schweinfurthii Engl. and maize cob on aflatoxin $\mathrm{B}_{1}$ toxicosis in broiler chickens. Advances in Animal Biosciences 1, 462-463.

Kermanshahi, H., Akbari, M. R., Maleki, M., \& Behgar, M. (2007). Effect of prolonged low level inclusion of aflatoxin $\mathrm{B}_{1}$ into diet on performance, nutrient digestibility, histopathology and blood enzymes of broiler chickens. Journal of Animal and Veterinary Advances 6(5), 686-692.

Liu, N., Wang, J. Q., Jia, S. C., Chen, Y. K., \& Wang, J. P. (2018). Effect of yeast cell wall on the growth performance and gut health of broilers challenged with aflatoxin $\mathrm{B}_{1}$ and necrotic enteritis. Poultry Science 97, 477-484.

Magnoli, A. P., Monge, M. P., Miazzo, R. D., Cavaglieri, L. R., Magnoli, C. E., Merkis, C. I., Cristofolini, A. L., Dalcero, A. M., \& Chiacchiera, S. M. (2011). Effect of low levels of aflatoxin B1 on performance, biochemical parameters, and aflatoxin $\mathrm{B}_{1}$ in broiler liver tissues in the presence of monenin and sodium bentonite. Poultry Science 90, 48-58.

Malekinezhad, P., Ellestad, L. E., Afzali, N., Farhangfar, S. H., Omidi, A., \& Mohammadi, A. (2021). Evaluation of berberine efficiency in reducing the effects of aflatoxin $\mathrm{B}_{1}$ and ochratoxin $\mathrm{A}$ added to male broiler rations. Poultry Science 100, 797-809.

Manlusoc, J. K. T., Hsieh, C. L., Hsieh, C. Y., Salac, E. S. N., Lee, Y. T., \& Tsai, P. W. (2019). Pharmacologic application, potentials of sulfated polysacchride from marine algae. Polymers 11, 1163.

Matur, E., Ergul, E., Akyazi, I., Eraslan, E., \& Cirakli, Z. T. (2010). The effects of Saccharomyces cerevisiae extract on the weight of some organs, liver, and pancreatic digestive enzyme activity in breeder hens fed diets contaminated with aflatoxins. Poultry Science 89(10), 2213-2220.

Molina-Alvarado, A., Zamora-Sanabria, R., \& GranadosChinchilla, F. (2017). A focus on aflatoxins in feedstuffs: Levels of contamination, prevalence, control strategies, and impacts on animal health. In Abdulra'uf, L. (Ed.). Aflatoxin: Control analysis, detection and health risks (115-152). London, UK: IntechOpen.

Nakavuma, J. L., Kirabo, A., Bogere, P., Nabulime M. M., Kaaya, A. N., \& Gnonlonfin, B. (2020). Awareness of mycotoxins and occurrence of aflatoxins in poultry feeds and feed ingredients in selected regions of Uganda. International Journal of Food Contamination 7, 1-10.

NRC (National Research Council). (1994). Nutrient requirements of poultry ( $9^{\text {th }}$ ed.). Washington DC, USA: National Academy Press.

Pizzolitto, R. P., Armando, M. R., Salvano, M. A., Dalcero, A. M., \& Rosa, C. A. (2013). Evaluation of Saccharomyces cerevisiae as an antiaflatoxicogenic agent in broiler feedstuffs. Poultry Science 92, 1655-1663.

Raju, M. V. L. N., \& Devegowda, G. (2000). Influence of esterified-glucomannan on performance and organ morphology, serum biochemistry and haematology in 
broilers exposed to individual and combined mycotoxicosis (aflatoxin, ochratoxin and T-2 toxin). Bristish Poultry Science 41, 640-650.

Rawal, S., Ji, E. K., \& Roger, C. (2010). Aflatoxin B B $_{1}$ in poultry: Toxicology, metabolism and prevention. Research in Veterinary Science 89(3), 325-331.

Richard, J. L. (2007). Some major mycotoxins and their mycotoxicoses - An overview. International Journal of Food Microbiology 119(1-2), 3-10.

Saminathan, M., Selamat, J., Abbasi Pirouz, A., Abdullah, N., \& Zulkifli, I. (2018). Effects of nano-composite adsorbents on the growth performance, serum biochemistry, and organ weights of broilers fed with aflatoxin-contaminated feed. Toxins 10, 345.

Shareef, A. M. (2010). Molds andmycotoxins in poultry feeds fromfarms of potentialmycotoxicosis. Iraqi Journal of Veterinary Sciences 24(1), 17-25.

Valchev, I., Kanakov, D., Hristov, T. S., Lazarov, L., Binev, R., Grozeva, N., \& Nikolov, Y. 2014. Investigations on the liver function of broiler chickens with experimental aflatoxicosis. Bulgarian Journal of Veterinary Medicine 17(4), 302-313.
Yang, J., Bai, F., Zhang, K., Lv, X., Bai, S., Zhao, L., Peng, X., Ding, X., Li, Y., \& Zhang, J. (2012). Effects of feeding corn naturally contaminated with $\mathrm{AFB}_{1}$ and $\mathrm{AFB}_{2}$ on performance and aflatoxin residues in broilers. Czech Journal of Animal Science 57(11), 506-515.

Yunus, A. W., Razzazi-Fazeli, E., \& Bohm, J. (2011). Aflatoxin $\mathrm{B}_{1}$ in affecting broiler's performance, immunity, and gastrointestinal tract: A review of history and contemporary issues. Toxins 3, 566-590.

Zaghini, A., Martelli, G., Roncada, P., Simioli, M., \& Rizzi, L. (2005). Mannanoligosaccharides and aflatoxin $\mathrm{B}_{1}$ in feed for laying hens: Effects on egg quality, aflatoxins $B_{1}$ and $M_{1}$ residues in eggs, and aflatoxin $B_{1}$ levels in liver. Poultry Science 84(6), 825-832. 